\title{
Gill damage and neurotoxicity of ammonia nitrogen on the clam Ruditapes philippinarum
}

\author{
Ming Cong $\cdot$ Huifeng $\mathrm{Wu}^{1} \cdot$ Haiping $\mathrm{Yang}^{2} \cdot \operatorname{Jianmin} \mathrm{Zhao}^{1} \cdot \operatorname{Jiasen}_{\mathrm{Lv}^{3}}$
}

Accepted: 8 February 2017 / Published online: 25 February 2017

(c) Springer Science+Business Media New York 2017

\begin{abstract}
Ammonia nitrogen has been a potential menace to aquatic animals along the coastline of China. Presently, the toxicological effects of ammonia nitrogen were mainly concentrated on fishes, while little attention has been paid to molluscs. In this study, the clam Ruditapes philippinarum was used as the target animal to investigate the toxic effects of ammonia nitrogen. Our results showed that ammonia exposure could significantly reduce the integrity of lysosomes in a dose-dependent manner. Metabolite analysis revealed that exposure doses and duration time of ammonia nitrogen could affect the variation profiles of gill metabolites. In detail, branched chain amino acids, glutamate, choline and phosphocholine were significantly decreased after a one-day exposure. Inosine and phenylalanine were found significantly increased and ATP was decreased after a three-day exposure. The changes of metabolites implied that metabolisms of muscle element, neurotransmission and cell apoptosis of gill tissues would be affected by ammonia exposure. Such inferences were supported by the diminished muscle element, decreased concentrations of
\end{abstract}

$\triangle$ Huifeng Wu

hfwu@yic.ac.cn

$\triangle$ Jianmin Zhao

jmzhao@yic.ac.cn

1 Key Laboratory of Coastal Environmental Processes and Ecological Remediation, Yantai Institute of Coastal Zone Research (YIC), Chinese Academy of Sciences (CAS); Shandong Provincial Key Laboratory of Coastal Environmental Processes, YICCAS, Yantai 264003, P. R. China

2 Institute of Oceanology \& Marine Fisheries, Nantong 226007, P. R. China

3 College of Life Sciences, Yantai University, Yantai 264005, P. R. China catecholamines and increased apoptosis rates, respectively. Therefore, we take advantage of metabolomics integrated with conventional biological assays to find out that ammonia exposure could cause lysosome instability, metabolic disturbance, aberrant gill structures and changes to neurotransmitters, and would result in mollusk gill dysfunction in feeding, respiration and immunity.

Keywords Ammonia nitrogen · Gill damage •

Neurotoxicity $\cdot$ Ruditapes philippinarum

$\begin{array}{ll}\text { Abbreviations } \\ \mathrm{NH}_{3} & \text { Un-ionized ammonia } \\ \mathrm{NH}_{4}{ }^{+} & \text {Ammonium ion } \\ \mathrm{NMDA}^{2} & \text { N-methyl-D-aspartic acid } \\ \text { TAN } & \text { Total ammonia-nitrogen } \\ \text { UIA } & \text { Unionized ammonia } \\ \text { PLS-DA } & \text { Partial least squares discriminant analysis } \\ \text { O-PLS- } & \text { Orthogonal projection to latent structure with } \\ \text { DA } & \text { discriminant analysis } \\ \text { One-way } & \text { One-way analysis of variance } \\ \text { ANOVA } & \\ \text { LSD } & \text { Least significant difference } \\ \text { NRRP } & \text { Neutral red retention periods } \\ \text { Ach } & \text { Acetylcholine } \\ \text { PC } & \text { Phosphatidylcholine } \\ \text { ATP } & \text { Adenosine triphosphates } \\ \text { IMP } & \text { Inosine monophosphates }\end{array}$

\section{Introduction}

With the rapid development of human society, many organic pollutants containing nitrogen have been produced 
from modern industry, agriculture and human daily activities. The organic-nitrogen pollutants discharged into the environment without strict disposal will be decomposed by microbes, and cause ammonia nitrogen pollution to the ecosystem. Ammonia in seawater exists in two forms, unionized ammonia $\left(\mathrm{NH}_{3}\right)$ and ammonium ion $\left(\mathrm{NH}_{4}{ }^{+}\right)$, depending on the $\mathrm{pH}$ value and temperature of the seawater (Emmerson et al. 1975). Un-ionized ammonia is known to be more toxic than ammonium ion, and causes many kinds of adverse effects to the metabolism, development and immunity of aquatic organisms (Randall and Tsui 2002; Reddy-Lopata et al. 2006; Maas et al. 2012).

Concerning the toxicity of ammonia nitrogen, it is reported that ammonia nitrogen can cross the blood-brain barrier of the vertebrate and produce toxic effects to the brain, leading to convulsions, coma, and death (Randall and Tsui 2002; Arafa and Atteia 2013). In mariculture, toxicological data about ammonia nitrogen have mainly come from fish so far. The toxic nature is interpreted as a high level of ammonia leading to the depolarization of neurons and activation of $\mathrm{N}$ methyl-D-aspartic acid (NMDA)-type glutamate receptor, which causes influxes of excessive $\mathrm{Ca}^{2+}$ and $\mathrm{K}^{+}$resulting in subsequent cell apoptosis in the brain (Randall and Tsui 2002). However, there are few studies on the toxicology of ammonia nitrogen in molluscs. It is reported ammonia nitrogen exposure to molluscs can cause reduced integrity of lysosome, decreased survival rates, impaired cellular and immune reactions, as well as disturbed energy allocation (Keppler 2007; Widman et al. 2008; Maas et al. 2012; Wang et al. 2012). Until now, there have been few detailed reports about the underlying mechanism of ammonia nitrogen to molluscs at tissue-, cell- and metabolic levels.

Tidal flat around the coastline is an important region for mariculture especially molluscs, yet the heavy pollution of ammonia nitrogen near the seashore brings great threat to the healthy development of molluscan mariculture (Watanabe et al. 2009, Liu et al. 2011). Thus, further investigation on the toxicological effects of ammonia nitrogen to marine molluscs is urgently required to broaden the knowledge base of invertebrate toxicology and contribute fundamental data to marine management. The clam Ruditapes philippinarum is an important bivalve mollusc cultured along the coastlines all over the world. Due to its limited mobility and high sensitive to pollutants, $R$. philippinarum can be used as an environmental indicator of anthropogenic pollution along coastal line (Watanabe et al. 2009, Zhang et al. 2014). In the present study, the clam $R$. philippinarum was used as the experimental animal and received ammonia nitrogen exposure at environmentally relevant concentrations to elucidate the adverse effects of ammonia nitrogen on molluscs and the underlying mechanisms.

According to the environmental bulletin of China in 2010, the concentration of ammonia nitrogen in the neritic seas of China ranged from 0 to $19.32 \mathrm{mg} / \mathrm{L}$ with an average of $1.82 \mathrm{mg} / \mathrm{L}$. However, a concentration of $0.02 \mathrm{mg} / \mathrm{L}$ of ammonia nitrogen is suggested to be the safe limit for mariculture animals (Water quality standard for fisheries, GB11607-89). Previous studies reported that $\mathrm{LC}_{50}$ values of ammonia nitrogen to $R$. philippinarum ranged from 0.65 $\mathrm{mg} / \mathrm{L}(168 \mathrm{~h})$ to $239 \mathrm{mg} / \mathrm{L}(24 \mathrm{~h}$ ) (Wang 1989; Wang et al. 2012). In order to make sure that the exposure concentration of ammonia nitrogen could cause toxicity to the clams without causing mass mortality, three environment-related doses of ammonia nitrogen were used in our first experiment to screen the proper doses by detecting lysosomal destabilization, which was a well-established indicator of cellular damage (UNEP/RAMOGE 1999; Keppler 2007; Aguirre-Martínez et al. 2013). In the second experiment, gill tissues of $R$. philippinarum were used to detect the variations in metabolism, histological structure and apoptosis rates upon ammonia nitrogen exposure, because the gills are regarded as a major tissue to contact with external environment and the first target of external contaminants (David et al. 2008; Natalotto et al. 2015).

\section{Materials and methods}

\section{Clams cultivation, ammonia nitrogen exposure and tissue sampling}

Adult clams $R$. philippinarum (averaging $3.62 \pm 0.28 \mathrm{~cm}$ in shell length) were collected from a relatively clean area in Yangma Island (with an average background concentration of $\left.0.0016 \mathrm{mg} / \mathrm{L} \mathrm{NH}_{3}-\mathrm{N}\right)$, Yantai city. The clams were acclimated for 8 days in aerated, filtered seawater $\left(19 \sim 20^{\circ}\right.$ C, $32 \mathrm{psu}$ ) and fed with mixture of Isochrysis galbana and Chlorella vulgaris Beij. The seawater was changed twice a day just before and $2 \mathrm{~h}$ past the feeding. A stock solution of high purity $\mathrm{NH}_{4} \mathrm{Cl}(1 \mathrm{~mol} / \mathrm{L})$ was used as the source of the total ammonia-nitrogen (TAN). Given that the temperature and $\mathrm{pH}$ value contribute to the ratio of unionized ammonia (UIA), the concentrations of UIA in each exposed group was calculated by the formula proposed by Emmerson et al. (1975), which was almost equal to the values determined by the known laboratory analysis ( $\mathrm{Li} \mathrm{1995).} \mathrm{Seawater} \mathrm{was}$ transferred from an un-polluted sea area and deposited at an air-conditioned room at $20^{\circ} \mathrm{C}$ after sand filtration. The $\mathrm{pH}$ value of seawater was measured each day and maintained at $8.0 \pm 0.1$. After the acclimation period, the clams were divided into four groups including control $(0 \mathrm{mg} / \mathrm{L}$ UIA), low $(0.1 \mathrm{mg} / \mathrm{L}$ UIA), medium $(0.5 \mathrm{mg} / \mathrm{L}$ UIA) and high $(1.0 \mathrm{mg} / \mathrm{L}$ UIA) groups (each with three replicates and 65 individuals in each replicate) to receive ammonia nitrogen exposure for 3 days. The actual concentrations of ammonia nitrogen were determined to be $0.001 \pm 0.0002$, 
$0.105 \pm 0.004,0.561 \pm 0.020$ and $1.137 \pm 0.035 \mathrm{mg} / \mathrm{L}$ for the control, low, medium and high group, respectively. According to USEPA (1998, 1999), food was withheld during the exposure. The clams were sampled at 3, 12, 24 and $72 \mathrm{~h}$, and the hemolymph was extracted by a syringe from the pericardial cavity of the clams.

In the former experiment, starvation caused significant disturbance to the stability of lysosome. In addition, higher mortality ( $18 \%$ over 3 -day's duration) was observed in the high group compared with the low and medium groups $(6 \sim$ $8 \%$ ). Based on the result from the former experiment, $R$. philippinarum were supplied with algae mixture to alleviate disturbance from starvation in the subsequent experiment. And the high concentration of ammonia nitrogen was excluded in the subsequent experiment to obtain useful and valid results. Gill tissues of the clams were collected at 1st and 3rd day post ammonia exposure. After dissection, part of the gill tissues was washed by filtered sterilized seawater and subject to apoptosis analysis. Another part of gill tissue was rapidly frozen in liquid nitrogen and used for detection of metabolites. In addition, a third part of gill tissue was quickly fixed in Bonn's liquid (saturated picric acid:formaldehyde:glacial acetic acid $=15: 5: 1 ; \mathrm{v} / \mathrm{v} / \mathrm{v}$ ) and used for histological analysis at the 3rd day. After the hemolymph was centrifuged at $3000 \mathrm{~g}$ for $2 \mathrm{~min}$ at $4{ }^{\circ} \mathrm{C}$, the supernatant was collected for neurotransmitters quantification. At each time point, eight clams were randomly picked and each clam was used as an individual.

\section{Analysis of destabilization of lysosomes}

Lysosome assay was processed as described by AguirreMartínez et al. (2013). Briefly, $500 \mu \mathrm{L}$ of hemolymph was collected from each individual clam by a $1-\mathrm{mL}$ syringe containing $500 \mu \mathrm{L}$ of pre-filtered seawater. After blending, $40 \mu \mathrm{L}$ of the mixture was pipetted onto a slide pre-treated with $5 \mu \mathrm{L}$ of poly-L-lysine and put into a moist chamber for 3 min to allow the haemocytes adhere to the glide. Then the slide was inclined to let the redundant fluid run down. About $40 \mu \mathrm{L}$ of seawater containing $0.1 \mathrm{mg} / \mathrm{ml}$ neutral red was added onto the slide and put into the moist chamber again for $15 \mathrm{~min}$. Excess solution was removed slightly before a coverslip was placed. Finally, the retention time of the neutral red dye in the lysosome was examined under a microscope $(400 \times$ magnification) at 15, 30, 45, 60, 90, 120 min. Such observation stopped when the ratio of dye-lost hemocytes was over $50 \%$. Destabilization of lysosomes was expressed as the retention time of neutral red, representing the time when more than $50 \%$ of the lysosomes released the neutral red dye into the cytosol. The shorter time for the lysosome to release out the dye suggested the heavier degree of the membrane was damaged.

\section{Metabolite extraction and ${ }^{1} \mathrm{H}$ NMR spectroscopy}

Polar metabolites in gill tissues of $R$. philippinarum were extracted according to the methods described by $\mathrm{Wu}(\mathrm{Wu}$ et al. 2008) and Liu (Liu et al. 2014). Briefly, $100 \mathrm{mg}$ of gill tissue was ground under liquid nitrogen, and $400 \mu \mathrm{L}$ of methanol and $85 \mu \mathrm{L}$ of water were added into the powder. After the mixture was collected into a tube, it was vortexed and centrifuged at $3000 \mathrm{~g}$ for $5 \mathrm{~min}\left(4^{\circ} \mathrm{C}\right)$. Then the supernatant was transferred into a $1.8 \mathrm{~mL}$ glass vial, and $200 \mu \mathrm{L}$ of chloroform and $440 \mu \mathrm{L}$ of water were added. Samples were vortexed and centrifuged, and the polar layer with polar metabolites were transferred into tubes and dried in a centrifugal concentrator. All the dried extracts were resuspended with $600 \mu \mathrm{L}$ of phosphate buffer $(100 \mathrm{mM}$ $\mathrm{Na}_{2} \mathrm{HPO}_{4}$ and $\mathrm{NaH}_{2} \mathrm{PO}_{4}$, including $0.5 \mathrm{mM} \mathrm{2,} \mathrm{2,} \mathrm{3,} \mathrm{3-d} \mathrm{(4)-}$ 3-(trimethylsilyl) propionic acid sodium salt (TSP) as the internal standard, $\mathrm{pH}$ 7.0) in $\mathrm{D}_{2} \mathrm{O}$ (deuteroxide). After vortex and centrifugation again, the supernatant of each sample was transferred into a NMR tube for further NMR analysis. ${ }^{1} \mathrm{H}$ NMR was performed by using a Bruker AV $500 \mathrm{NMR}$ spectrometer at $500.18 \mathrm{MHz}$ according to $\mathrm{Wu}$ et al. (2008). All ${ }^{1} \mathrm{H}$ NMR spectra were phased, baselinecorrected, and calibrated (TSP at $0.0 \mathrm{ppm}$ ) manually using TopSpin (version 2.1, Bruker).

\section{Histopathology analysis}

The operational approach of histopathology analysis was adopted from Al-Subiai (Al-Subiai et al. 2011) with slight modification. Briefly, after the gill samples were fixed in Bonn's liquid for $24 \mathrm{~h}$, they were washed three times in $70 \%$ ethyl alcohol and dehydrated in a graded series of alcohol. Then the gills were washed in xylene for three times and embedded in paraffin. Gill sections with $6-8 \mu \mathrm{m}$ thickness were done with a microtome (KD-3358, KEDEE), and stained with hematoxylin and eosin on a LST94 Linear Slide Stainer (Hestion, Australia). After sealed by neutral balsam, the gill sections were observed under an Olympus light microscope at magnification of $\times 200$ and $\times 400$.

\section{Apoptosis detection}

After the gill tissues were dissected, one half of each sample was used to detect the apoptosis ratios of gill cells by flow cytometry. The rest was used to test the activation of caspase-3. The combination of flow cytometry and caspase3 activity assay would evaluated complentarily about the apoptosis effects of ammonia nitrogen exposure to the clam R. philippinarum.

For the apoptosis ratio analysis, the gill tissues were cut up by a surgical scissores into cell suspesion which was filtered by boulting cloth with 300 mesh. The cell suspesion 
was then centrifuged at $1000 \mathrm{~g}$ for $3 \mathrm{~min}$. Cell deposit was re-suspended by $500 \mu \mathrm{L}$ of Annexin V-FITC buffer. Quantification of the population of the apoptotic cells was determined by the Annexin V/PI double staining assay. The following procedure was conducted as the mannual protocol of the Annexin V-FITC Apoptosis Detection Kit (Beyotime). In brief, $5 \mu \mathrm{L}$ of Annexin V-FITC and $5 \mu \mathrm{L}$ of PI were added to $500 \mu \mathrm{L}$ of gill cells suspension, and the reaction mixture was incubated in dark at room temperature for $10 \mathrm{~min}$. Then the gill cells were measured by flow cytometry in accordance with the instruction. A minimum of about 10,000 cells were detected and analyzed. Each percentage of FITC and PI positive cells was calculated respectively. The cells show four different cell populations marked as the follows: PI-positively and FITC-negatively stained cells showing dead cells (upper left, Q1), FITC and PI double-stained cells showing late apoptosis (upper right, Q2), double-negative cells showing live cell population (lower left, Q3) and FITC-positively and PI-negatively stained cells showing early apoptosis (lower right, Q4).

Detection of caspase-3 activities was performed according to the protocol of caspase-3 kit (Nanjing Jiancheng). Briefly, the gill tissue was homonized in cold lysate and centrifigued at $10,000 \mathrm{~g}$ for $15 \mathrm{~min}$. The supernant was collected to test the activity of caspase- 3 and the concentration of total protein. Acetyl-Asp-Glu-Val-Asp pnitroanilide (Ac-DEVD-pNA) was used as a fluorogenic substrate that could be cleaved specifically by caspase- 3 . The activities of caspase- 3 in different groups were determined by measuring the absorbance of free pNA at $405 \mathrm{~nm}$ after incubation at $37^{\circ} \mathrm{C}$ for $6 \mathrm{~h}$. One unit of caspase- 3 is defined as the amount of enzyme that will cleave $1.0 \mathrm{nmol}$ of the colorimetric substrate Ac-DEVD-pNA per hour at 37 ${ }^{\circ} \mathrm{C}$ under saturated substrate concentrations. The activation ratio of caspase-3 in the stressed group was determined as $\mathrm{OD}_{\text {stressed group }} / \mathrm{OD}_{\text {negative control. }}$.

\section{Quantification of neurotransmitters}

Norepinephrine in the supernatant of hemolymph was quantified according to the methods of Karim et al. (2007) and Zhou et al. (2011) with some modifications. In brief, $200 \mu \mathrm{L}$ of standard norepinephrine solutions $(2.5,25,50$, 100,150 and $250 \mathrm{ng} / \mathrm{mL}$ ) or supernatant samples were added to $200 \mu \mathrm{L}$ of $0.30 \% \mathrm{Hg}\left(\mathrm{NO}_{3}\right)_{2}, 400 \mu \mathrm{L}$ of $15 \%$ acetone and $200 \mu \mathrm{L}$ of $1.0 \mathrm{M}$ ethylenediamine solutions in succession. Then the mixture was vortexed fully, and 800 $\mu \mathrm{L}$ of $0.4 \mathrm{M} \mathrm{HCl}$ was added to neutralize the excess ethylenediamine. After the addition of $800 \mu \mathrm{L}$ of boric buffer (pH 9.0), the mixture was incubated at $30^{\circ} \mathrm{C}$ for $12 \mathrm{~min}$ and cooled to the room temperature. Then $1.4 \mathrm{~mL}$ of deionized water was added to the mixture and vortexed. A fluorospectrophotometer (LS 55, PerkinElmer) was used to detect the fluorescence intensity of the mixture with excitation at $507 \mathrm{~nm}$ and excitation at $420 \mathrm{~nm}$. The norepinephrine concentration of each sample was calculated according to the generated standard curve by measuring their fluorescence intensity.

The detection method for epinephrine was adopted from Zhou et al. (2011) and Guo et al. (2005) with slight modifications. Briefly, $200 \mu \mathrm{L}$ of standard epinephrine solutions $(2.5,25,50,100,150$ and $250 \mathrm{ng} / \mathrm{mL})$ or supernatant samples were added to $200 \mu \mathrm{L}$ of $2 \%$ formaldehyde and vortexed for $3 \mathrm{~min}$. Then $400 \mu \mathrm{L}$ of $0.1 \mathrm{M}$ borax buffer solution ( $\mathrm{pH} 9.5$ ) and $400 \mu \mathrm{L}$ of $0.25 \%$ potassium hexacyanoferrate solution were added to the mixture and vortexed. After that, $320 \mu \mathrm{L}$ of $0.15 \%$ ascorbic acid solution was added and vortexed. The mixture was heated at $100{ }^{\circ} \mathrm{C}$ for $2 \mathrm{~min}$ and cooled quickly to room temperature. Then $2.28 \mathrm{~mL}$ of deionized water was added, and the fluorescence intensity of the mixture was measured with excitation at $428 \mathrm{~nm}$ and emission at $498 \mathrm{~nm}$. Similarly, the epinephrine concentrations in the samples were calculated according to the generated standard curve by measuring their fluorescence intensity.

The concentration of dopamine was assayed by a mollusk dopamine ELISA kit (Nanjing Jiancheng). It is based on the principle of double-antibody sandwich technique to detect clam dopamine. Fifty microliter of dopamine standard or $40 \mu \mathrm{L}$ of hemolymph sample and $10 \mu \mathrm{L}$ of dopamine-antibody were added to the small wells which were pre-coated with mollusk dopamine monoclonal antibody. After $50 \mu \mathrm{L}$ of streptavidin-HRP was added, the plate was sealed with a membrane and placed at $37^{\circ} \mathrm{C}$ for $60 \mathrm{~min}$. Then the plate was washed five times and added chromogen solutions, followed by incubation at $37^{\circ} \mathrm{C}$ for $10 \mathrm{~min}$. After the stop solution was added, OD value was measured within $10 \mathrm{~min}$ at $450 \mathrm{~nm}$. A standard curve of dopamine was got by five concentrations $0,1.6 \times 10^{-6}, 8.0 \times 10^{-7}, 4 \times 10^{-7}$ and $2.0 \times 10^{-7} \mathrm{~g} / \mathrm{L}$. And the dopamine concentrations in the samples were then calculated by comparing the sample OD values to the standard curve.

\section{Data analysis}

For metabolomic analysis, spectral pre-processing and multivariate data analysis were carried out as described by Liu et al. (2014). Briefly, all one dimensional ${ }^{1} \mathrm{H}$ NMR spectra were converted to a data matrix using the customwritten ProMetab software in Matlab version 7.0 (Parsons et al. 2007). After the data were mean-centered, partial least squares discriminant analysis (PLS-DA) and orthogonal projection to latent structure with discriminant analysis $(\mathrm{O}-$ PLS-DA) were performed sequentially to uncover and extract the statistically significant metabolite variations related to ammonia nitrogen challenges. The model 
coefficients were calculated by incorporating the weight of the variables into the coefficients to enhance the interpretability of the model. Validation of the model was conducted using a 10-fold cross validation, and the cross-validation parameter $\mathrm{Q}^{2}$ was calculated, which over 0.4 was considered to be feasible. Metabolites in different challenged groups were assigned following the tabulated chemical shifts (Liu et al. 2014) and the software, Chenomx (Evaluation Version, Chenomx Inc., Edmonton, Alberta, Canada). The metabolic differences responsible for the classifications between the control and the ammonia nitrogen-exposed groups (Low or Medium) could be detected in the coefficient-coded loadings plot generated by using MATLAB (V7.0, the Mathworks Inc., Natwick, USA) with an in-house developed program and were colorcoded with absolute value of coefficients $(r)$.

All the other biological data were given as means \pm S.D. The data were subjected to one-way analysis of variance (one-way ANOVA) followed by least significant difference (LSD) analysis, and statistical significance was defined at $p<0.05$.

\section{Results}

\section{Analysis of destabilization of lysosomes}

At each time point, the neutral red retention periods (NRRPs) of the ammonia-nitrogen exposed clams exhibited a consistently down-regulated trend as the exposure concentration increased (Fig. 1). The NRRPs in the medium and high groups were significantly shorter $(p<0.05$ and $p<0.001$, respectively) compared with that of the control group at $3 \mathrm{~h}$. As time elapsed, the NRRPs of the low, medium and high groups were all significantly decreased $(p<0.05, p<0.001$ and $p<0.001$, respectively) compared with the control group at $12 \mathrm{~h}$. After one-day exposure, NRRP of the low group exhibited extreme significance $(p<0.001)$ compared with the control group, and so did the medium and high group $(p<0.001$ and $p<0.001$, respectively). Three days later, extremely significant differences were observed in the three exposed groups $(p<0.001$, $p<0.001$ and $p<0.001$, respectively). In addition, NRRP in the control group decreased at 24 and $72 \mathrm{~h}$ compared with that at $3 \mathrm{~h}(p<0.01$ and $p<0.001$, respectively), which suggested that food shortage affected greatly the stabilization of lysosomes.

\section{Metabolite analysis}

The cross-validation parameter $\mathrm{Q}^{2}$ in each metabolic analysis was over 0.4 , which suggested that the PLS-DA models were robust. Metabolic responses of the exposed

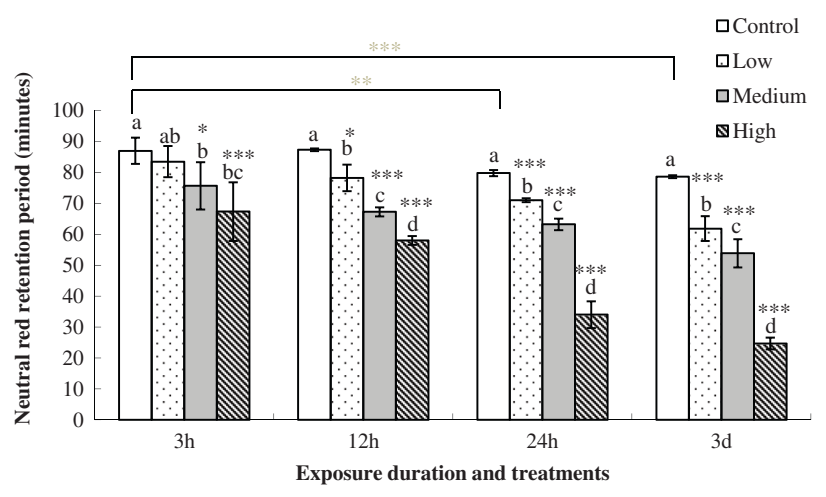

Fig. 1 Effect of ammonia exposure on lysosomal destabilization in $R$. philippinarum. Column data marked with different letters indicate significant difference $(p<0.05)$. Asterisks denote significant difference between the exposed and the control groups. Three asterisks indicate significance at $p<0.001$, two asterisks indicate significance at $p<0.01$, and one asterisk indicates significance at $p<0.05$. Light grey asterisks denote the difference between the NRRPs of the control group at different sampling points. Values are expressed as mean $\pm \mathrm{SD}$

clams were found significantly varied, and the varied metabolites with highly significances were shown in Table 1. In detail, branched chain amino acids (including valine, leucine and isoleucine), glutamate, choline and phosphocholine in both of the low and medium groups were significantly decreased after one-day of exposure. However, inosine and phenylalanine were detected to be significantly increased, while ATP was significantly decreased in both stressed groups after exposure for three days.

\section{Histopathology analysis}

The histological observations of clam gills for the control, low and medium groups were displayed in Fig. 2. In the control group (Fig. 2a), the gill filament could be clearly discerned with three zones, the frontal zone with dense cilia, intermediate part with less cilia and the abfrontal part. Inside each filament, there was a blood sinus lined by basal layer cells. At the base of the gill filaments, there were distinct muscular elements distributed longitudinally. Many cells distributed inside the blood sinus and around the longitudinal muscle, and their nucleuses were stained blue with haematoxylin. Overall, the gill tissue was in a regular order.

In the low group (Fig. 2b), cilia were slightly rarefied and differences among the three cilium zones were apparently indistinct. Inside the filaments, the basal layer became unclear. The stained nuclei inside the blood sinus almost vanished. The longitudinal muscle was reductive compared with the control. The gill tissue became loose with some large vacuoles scattered at the base of gill filaments.

In the medium group (Fig. 2c), the gill tissue seemed paralyzed. Some of the filaments were stretched and some 
Table 1 Different metabolites in gills after ammonia nitrogen exposure

\begin{tabular}{|c|c|c|c|}
\hline \multicolumn{2}{|l|}{ 1st (Control vs. low) } & \multicolumn{2}{|l|}{ 1st (Control vs. medium) } \\
\hline Increased & Decreased & Increased & Decreased \\
\hline & Valine & Alanine & Valine \\
\hline Succinate & Leucine & Acetate & Leucine \\
\hline \multirow[t]{11}{*}{ Unknown (5.96 ppm) } & Isoleucine & Glutamine & Isoleucine \\
\hline & Threonine & Aspartate & Glutamate \\
\hline & Arginine & Asparagine & Choline \\
\hline & Glutamate & Betaine & Phosphocholine \\
\hline & Glutamine & ATP & Unknown 1 (3.63 ppm) \\
\hline & Choline & & Inosine \\
\hline & Phosphocholine & & Glucose \\
\hline & Hypotaurine & & Glycogen \\
\hline & Unknown 2 (4.15 ppm) & & Histidine \\
\hline & & & Phenylalanine \\
\hline & & & Unknown 2 (7.94 ppm) \\
\hline \multicolumn{2}{|l|}{ 3rd (Control vs. low) } & \multicolumn{2}{|l|}{ 3rd (Control vs. medium) } \\
\hline Increased & Decreased & Increased & Decreased \\
\hline Unknown 1 (3.63 ppm) & ATP & Succinate & $\beta$-alanine \\
\hline Unknown 2 (3.85 ppm) & & Phosphocholine & Glutamine \\
\hline Inosine & & Unknown 1 (3.63 ppm) & Aspartate \\
\hline \multirow[t]{4}{*}{ Phenylalanine } & & Unknown 2 (3.85 ppm) & ATP \\
\hline & & Unknown 3 (5.96 ppm) & \\
\hline & & Inosine & \\
\hline & & Phenylalanine & \\
\hline
\end{tabular}

were broken at the front part. Inside of the filament, basal layer was almost vanished. Compared with the control group, the longitudinal muscle decomposed worse in the medium ammonia-exposed group. In addition, there were some xenobiotic substances stained lightly in the mediumexposed gills.

\section{Apoptosis detection}

Apoptosis ratios induced by ammonia nitrogen exposure were quantitatively detected by flow cytometry (Fig. 3). Concerning the early apoptosis rates (Fig. 4), the medium group was significantly higher $(p<0.05)$ than the control after one-day exposure. As time elapsed, the early apoptosis rates of both the low and medium groups exhibited significant increments compared with the control $(p<0.05)$ after three days of exposure.

Analysis of activation ratio of caspase-3 (Fig. 5) revealed that one-day exposure of ammonia nitrogen significantly induced caspase-3 activities in both exposed groups $(p<$ $0.001)$. And the up-regulation trends of the low and medium groups continued after three-day exposure $(p<0.05$ and $p<0.01$, respectively).

\section{Neurotransmitters quantification}

After one-day exposure, no significant difference in the norepinephrine concentration was observed between the low-group and the control (Fig. 6a). However, the mediumgroup decreased significantly $(p<0.05)$ compared with the control. After three days of exposure, the norepinephrine concentration of the low-group decreased extremely significantly $(p<0.01)$, while the norepinephrine concentration of the medium-group increased to a normal level compared with the control.

As for the variation trends of epinephrine (Fig. 6b), ammonia nitrogen exposure of medium concentration significantly decreased $(p<0.01)$ the concentration of epinephrine compared with the control after one-day exposure. And the low and medium groups exhibited significant decrements compared with the control $(p<0.001$ and $p<$ 0.01 , respectively) after three days of exposure. However, no significant difference of dopamine concentration was 

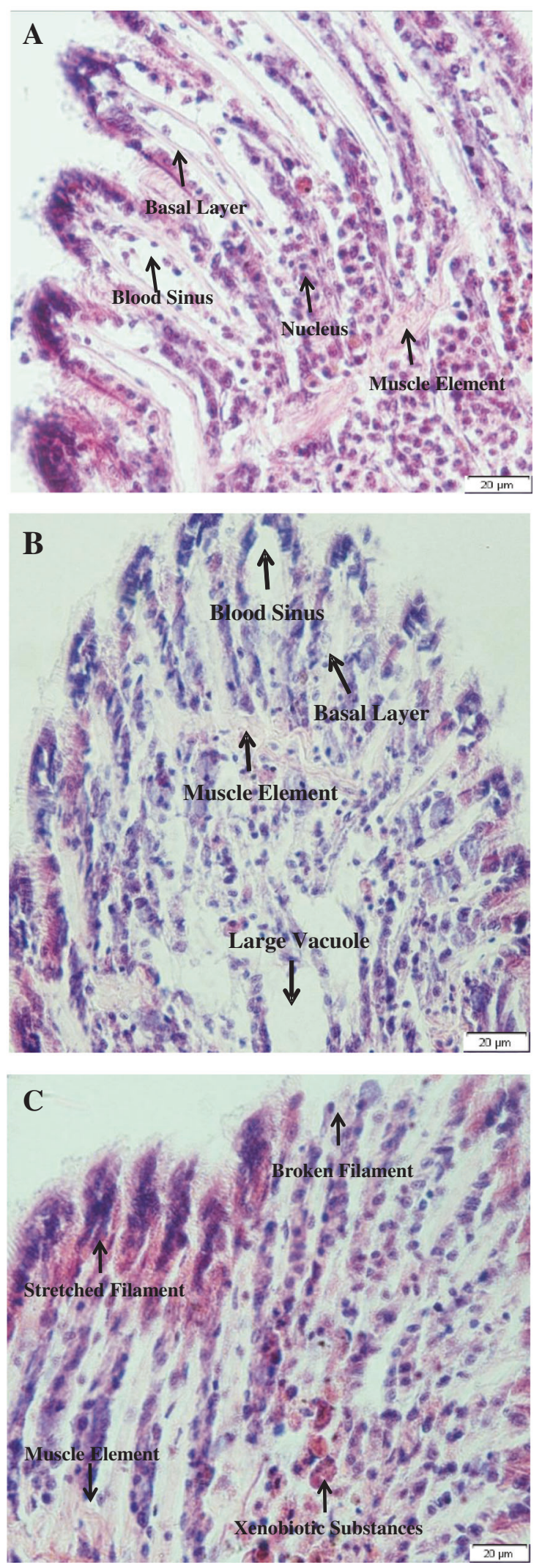

Fig. 2 Paraffin section of $R$. philippinarum gill filament stained by hematoxylin eosin stain after exposure to ammonia nitrogen for $72 \mathrm{~h}$ (Magnification $\times 400$ ). a Paraffin section of the control group; $\mathbf{b}$ Paraffin section of the low group; $\mathbf{c}$ Paraffin section of the medium group detected among the three groups during the three-day exposure (Fig. 6c).

\section{Discussion}

Ammonia is regarded as an important toxic component of sediment to the benthonic animals (Ankley et al. 1990, Ho et al. 2002), including $R$. philippinarum which is widely distributed along the neritic sea. Gill tissue of clam $R$. philippinarum plays vital roles in many physiological processes including respiration, feeding and immune defense. Besides, gill contains epithelial cells that are in direct contact with the external environment, and is prone to be affected by the pollutants, including ammonia nitrogen. Therefore, it is meaningful to investigate the changes of gill tissues in metabolism, anatomy structures, cell apoptosis, and neurotransmission to preliminarily understand the toxicological mechanism of ammonia nitrogen on clams.

In this study, lysosome membrane stabilization was used as an indicator of cellular health status of clams according to previous studies (Aguirre-Martínez et al. 2013). When there was a sudden food shortage, the decreased retention periods of neutral red in the control clams suggested that food shortage could cause cellular damage to the normal clams. Similar phenomena were also detected in oysters Crassotrea gigas (Thunberg) (Zhang and Li 2006). Therefore, the clams were fed during the subsequent experiment period. During the exposure experiment, the seawater-changing mode excluded influence of excess food nitrogen on the clams. As for the selection of ammonia nitrogen exposure concentrations, each concentration could cause significant decrements in lysosome membrane stabilization, which was consistent to the results in mussel (Fang et al. 2008). Our study also revealed that higher concentration of ammonia nitrogen would lead to degraded health of the clam.

Metabolomics is a newly developed 'omic' technique that focuses on the systematic study of metabolites during cellular processes, which has been widely used in environmental toxicology (Lindon et al. 2000; Liu et al. 2014). In the present study, metabolomics techniques were integrated with conventional biological and biochemistry assays to find out the underlying mechanisms of molluscs exposed to elevated levels of ambient ammonia nitrogen. The concentrations of branched chain amino acids, glutamate, choline and phosphocholine were found to decrease significantly in both ammonia nitrogen-exposed groups, implying abnormity in muscle and neurotransmitter metabolisms. Firstly, branched amino acids are convinced to play central roles in ameliorating muscle catabolism (Mizuguchi et al. 2015). The decrement of branched amino acids suggested that more muscle fibers were decomposed compared with the control. The assumption was proved by 

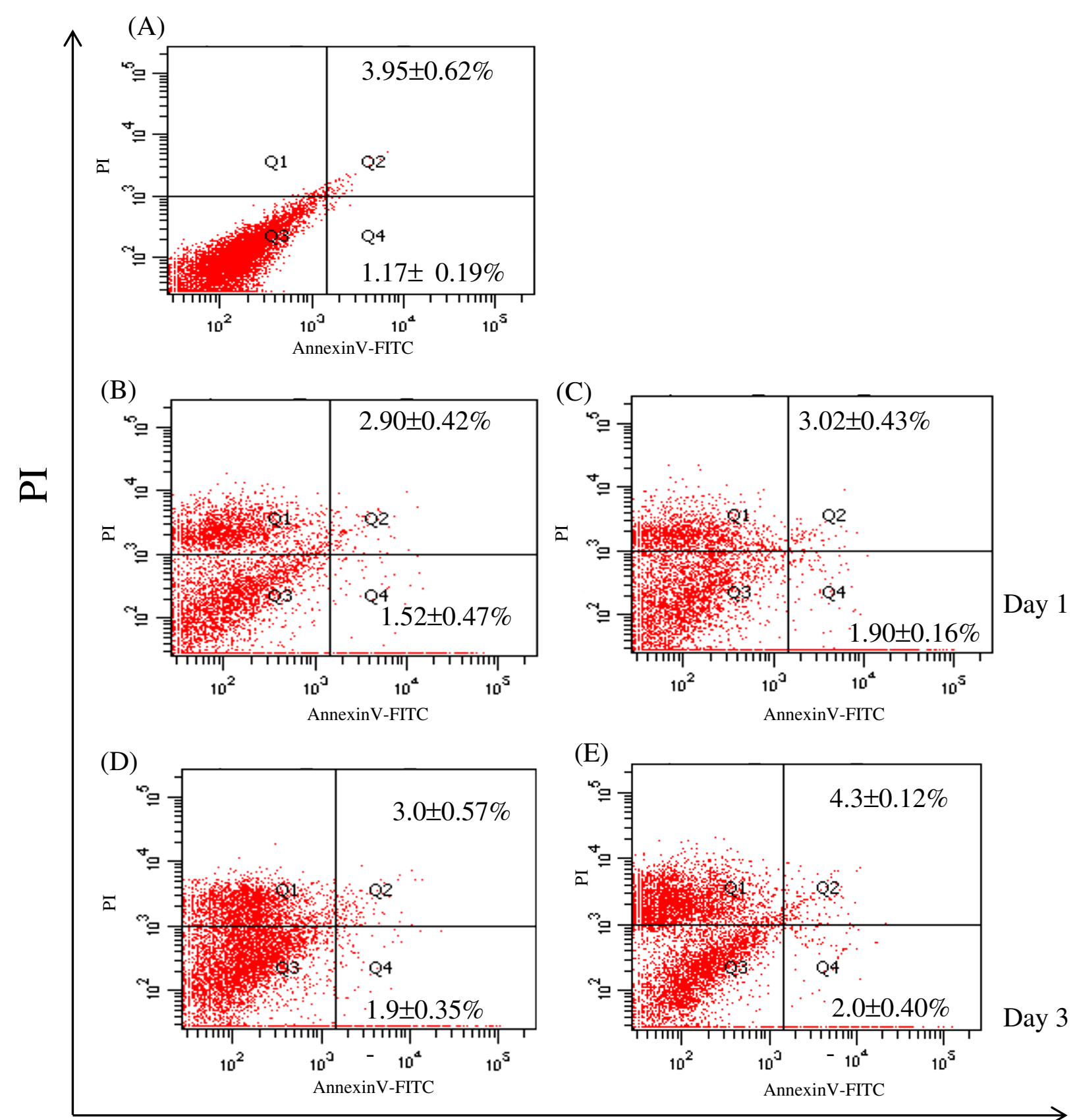

\section{Annexin V-FITC}

Fig. 3 Characterization of apoptotic gill cells by flow cytometry. Q1 shows the necrotic cells, Q2 shows the late apoptotic cells, Q3 shows intact cells and Q4 shows the early apoptotic cells. a Control

the histopathologic observation that some muscle fibers in the gill filament diminished after ammonia-nitrogen exposure. Since muscle fibers are most longitudinal and distribute in the inter-filament tissue junctions (Wang 1989; Gainey et al. 2003), the diminished muscle fibers probably contributed to the loose gill structure after exposure for three days. Therefore, it can be expected that the normal group; b low group after one day of exposure; c medium group after one day of exposure; d low group after three days of exposure; $\mathbf{e}$ medium group after three days of exposure

functions of gill filament including respiration, filter-feeding were restrained after ammonia exposure. Secondly, glutamate is a major neurotransmitter and involved in local aerobic glycolysis in astrocytes (Pellerin and Magistretti 1994; Nesic et al. 1996). The decrement of glutamate after one day exposure of ammonia nitrogen suggested that energy production from glycolysis in molluscs neural 


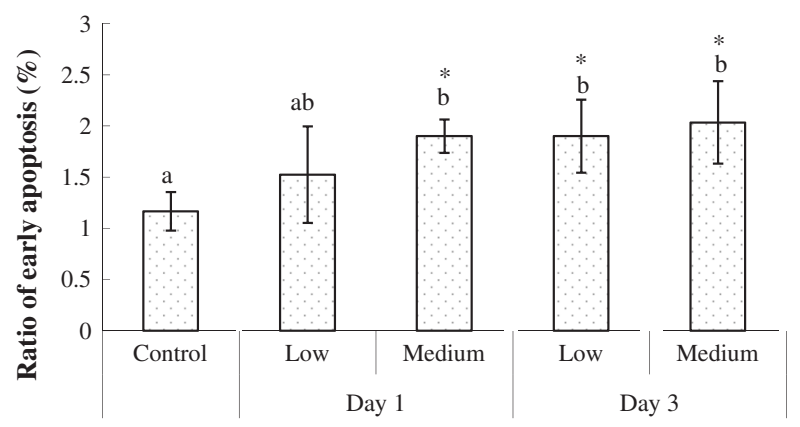

Exposure duration and Treatments

Fig. 4 Ratio of early apoptosis in gill cells after ammonia exposure. Column data marked with different letters indicate significant difference $(p<0.05)$. Asterisks denote significant difference between the exposed and the control groups. One asterisk indicates significance at $p<0.05$. Values are expressed as mean $\pm \mathrm{SD}$

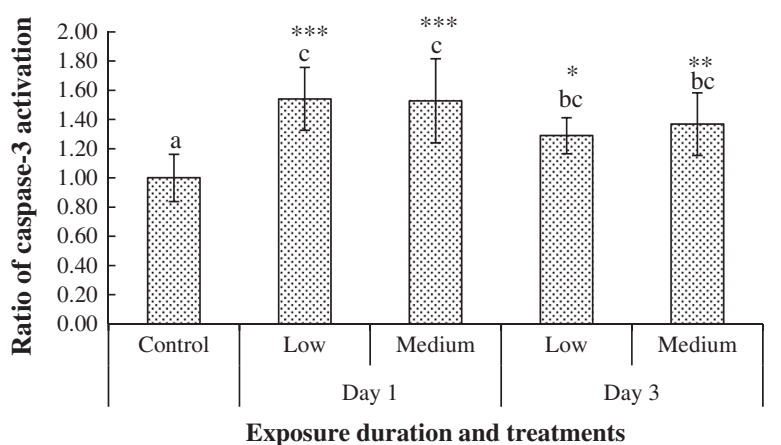

Fig. 5 Ratio of caspase-3 activation in gill cells after ammonia exposure. Column data marked with different letters indicate significant difference $(p<0.05)$. Asterisks denote significant difference between the exposed and the control groups. Three asterisks indicate significance at $p<0.001$, two asterisks indicate significance at $p<$ 0.01 , and one asterisk indicates significance at $p<0.05$. Values are expressed as mean $\pm \mathrm{SD}$

system was weakened, which would cause the gill tissue in an obtuse state to external stimulus. According to Randall (Randall and Tsui 2002; Bobermin et al. 2015), ammonia nitrogen damaged the central nervous system of vertebrates by causing high level of extracellular glutamate, which was different to the present study. Although glutamate was involved in the toxicological reactions of both fishes and molluscs to ammonia exposure, mechanisms underlying the different effects between vertebrate and invertebrate were still unknown and required further investigation. Thirdly, choline is an essential precursor of the neurotransmitter acetylcholine (ACh) and the major constituent of membrane phosphatidylcholine (PC). Phosphocholine is one of the intermediates during the synthesis reaction of $\mathrm{PC}$ from choline and ATP catalyzed by choline kinase (Wurtman et al. 2010). Significant decrement of choline was reported to induce apoptosis (Yen et al. 2001; Shen et al. 2012).

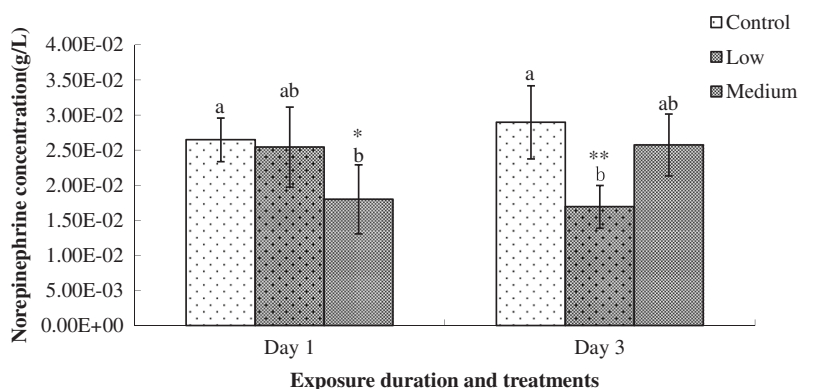

(B)
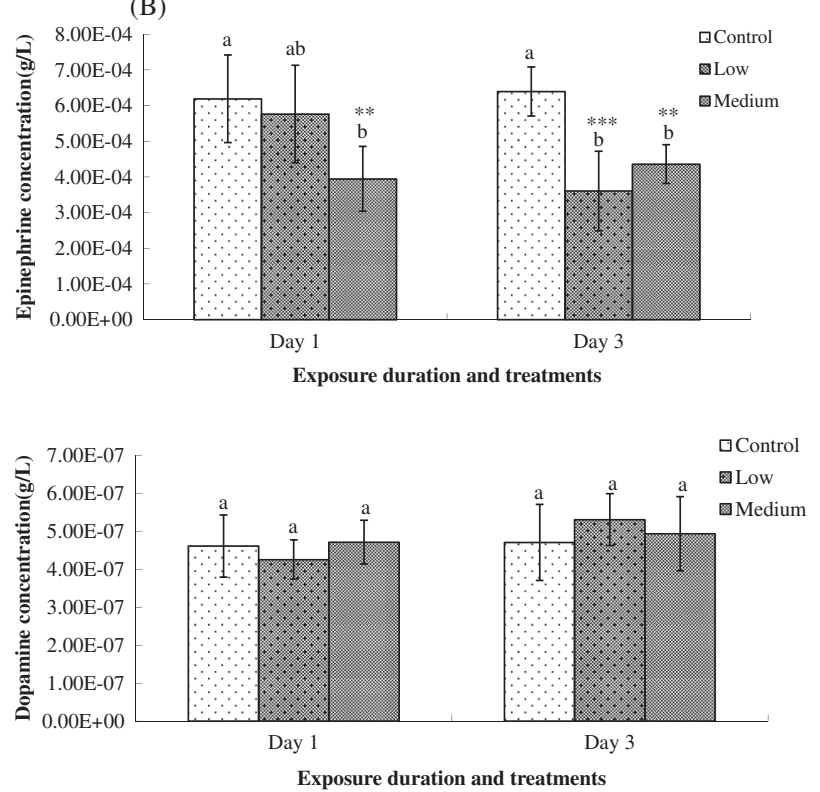

Fig. 6 Concentrations of catecholamine neurotransmitters after ammonia nitrogen exposure. Column data marked with different letters indicate significant difference $(p<0.05)$, and different columns sharing a same letter denote no significant difference between them $(p>$ $0.05)$. Asterisks denote significant difference between the exposed and the control groups. Three asterisks indicate significance at $p<0.001$, two asterisks indicate significance at $p<0.01$, and one asterisk indicates significance at $p<0.05$. Values are expressed as mean $\pm \mathrm{SD}$. a Concentrations of norepinephrine; $\mathbf{b}$ concentrations of epinephrine; $\mathbf{c}$ concentrations of dopamine

Similarly, the decreased concentrations of choline and phosphocholine in the present study suggested that metabolisms of ACh and PC were perhaps impaired, leading to neuro-transmission perturbation and cell apoptosis.

Caspase-3 is regarded as the critical determinant of genotoxic apoptosis (Portera and Jänicke 1999; Mazumder et al. 2008). Significant increments of caspase-3 activation in both stressed groups suggested that one day exposure at very low concentrations of ammonia nitrogen could trigger the apoptosis program in gill cells. In addition, it was recently reported that increased apoptosis rates were correlated with the decreased ATP level (Yang et al. 2012), which was consistent with our current results of metabolite analysis. Despite the fact that apoptotic cells would be 
cleared in a programmed pathway, seriously damaged membrane would cause not only apoptosis but necrosis phenomena (Dwivedi et al. 2012), which would cause dysfunction of the gill tissue.

After three days of ammonia exposure, significant increments of inosine and phenylalanine, together with decrement of ATP, suggested that many biological processes especially energy and catecholamines metabolism were perturbed in gill tissue of both stressed groups. Inosine is nucleoside that has been broken down from adenosine catalyzed by adenosine deaminase. The accumulation of inosine suggested that more adenosine triphosphates (ATPs) were used to release energy and produced more inosine monophosphates (IMPs) which were catalyzed into inosine by dephosphorylase (Vetharaniam et al. 2010). This speculation was in accordance with the decrement of ATP in both ammoniaexposed groups. As for phenylalanine, the significant increment might cause disturbances in many physiological processes. For example, phenylalanine can be transformed into tyrosine, and tyrosine is the important precursor for a variety of biologically important substances, such as catecholamines (norepinephrine, epinephrine and dopamine), thyroid hormones, melanin pigments and proteins (Levine and Conn 1967). Therefore, it was expected that neurotransmission by catecholamines in gill tissue of clams would be restrained after three days of ammonia exposure. Such opinion was proved by the variation profiles of three kinds of catecholamines, two of which exhibited significant decrements after ammonia exposure. It can be clearly inferred that ammonia nitrogen has neurotoxic effects to the marine bivalve $R$. philippinarum and the clam spends more energy to counter against the toxicity of ammonia nitrogen.

\section{Conclusion}

We investigate the toxicological effects of ammonia nitrogen on marine bivalve $R$. philippinarum. It was found that ammonia nitrogen could destabilize the membrane of lysosomes, cause apoptosis of gill cells, and decompose the muscle elements in the gill tissues. Moreover, the significant variations of branched amino acids and some important neurotransmitters revealed metabolic disturbance in the gills. These results indicated that ammonia nitrogen caused significant gill damage and neurotoxicity on marine bivalves, which would lead to dysfunction of gill tissue in feeding, respiration and immunity.

Acknowledgements This study was funded by Natural Science Foundation of China (NSFC 41406132), Natural Science Foundation of Jiangsu Province (JSSFC BK2012660), the Strategic Priority Research Program of the Chinese Academy of Sciences (XDA11020702) and Public Science and Technology Research Funds Projects of Ocean (No. 201505022).
Compliance with ethical standards

Conflict of interest The authors declare that they have no conflict of interest.

Ethical approval All applicable international, national, and/or institutional guidelines for the care and use of animals were followed.

\section{References}

Aguirre-Martínez GV, Buratti S, Fabbri E, Del Valls AT, Martín-Díaz ML (2013) Using lysosomal membrane stability of haemocytes in Ruditapes philippinarum as a biomarker of cellular stress to assess contamination by caffeine, ibuprofen, carbamazepine and novobiocin. J Environ Sci-China 25:1408-1418

Al-Subiai SN, Moody AJ, Mustafa SA, Jha AN (2011) A multiple biomarker approach to investigate the effects of copper on the marine bivalve mollusc, Mytilus edulis. Ecotoxicol Environ Saf 74:1913-1920

Ankley GT, Katko A, Arthur JW (1990) Identification of ammonia as an important sediment-associated toxicant in the lower fox river and Green Bay, Wisconsin. Environ Toxicol Chem 9:313-322

Arafa MH, Atteia HH (2013) Sildenafil citrate attenuates the deleterious effects of elevated ammonia. Toxicol Mech Methods 23:402-411

Bobermin LD, Hansel G, Scherer EBS, Wyse ATS, Souza DO, Quincozes-Santos A, Gonçalves C-A (2015) Ammonia impairs glutamatergic communication in astroglial cells: protective role of resveratrol. Toxicol in Vitro 29:2022-2029

David JADO, Salaroli RB, Fontanetti CS (2008) Fine structure of Mytella falcate (Bivalvia) gill filaments. Micron 39:329-336

Dwivedi S, Saquib Q, Al-Khedhairy AA, Musarrat J (2012) Butachlor induced dissipation of mitochondrial membrane potential, oxidative DNA damage and necrosis in human peripheral blood mononuclear cells. Toxicology 302:77-87

Emmerson K, Russo RC, Lund RE, Thurston RV (1975) Aqueous ammonia equilibrium calculations: effects of $\mathrm{pH}$ and temperature. J Fish Res Board Can 32:2379-2383

Fang JKH, Wu RSS, Chan AKY, Yip CKM, Shin PKS (2008) Influences of ammonia-nitrogen and dissolved oxygen on lysosomal integrity in green-lipped mussel Perna viridis: Laboratory evaluation and field validation in Victoria Harbour, Hong Kong. Mar Pollut Bull 56:2052-2058

Gainey JRLF, Walton JC, Greenberg MJ (2003) Branchial musculature of a Venerid clam: pharmacology, distribution, and innervation. Biol Bull 204:81-95

Guo Y, Yang J, Wu X, Du A (2005) A sensitive fluorimetric method for the determination of epinephrine. J Fluoresc 15:131-136

Ho KT, Burgess RM, Pelletier MC, Serbst JR, Ryba SA, Cantwell MG, Kuhn A, Raczelowski P (2002) An overview of toxicant identification in sediments and dredged materials. Mar Pollut Bull 44:286-293

Karim MM, Alam SM, Lee SH (2007) Spectrofluorimetric estimation of norepinephrine using ethylenediamine condensation method. J Fluoresc 17:427-436

Keppler CJ (2007) Effects of ammonia on cellular biomarker responses in oysters (Crassostrea virginica). Bull Environ Contam Toxicol 78:63-66

Levine RJ, Conn HO (1967) Tyrosine metabolism in patients with liver disease. J Clin Invest 46:2012-2020

Li AY (1995) Seawater chemistry. China Agriculture Press, Beijing, China 
Lindon JC, Nicholson JK, Holmes E, Everett JR (2000) Metabonomics: metabolic processes studied by NMR spectroscopy of biofluids. Concepts Magn Reson 12:289-320

Liu S, Lou S, Kuang C, Huang W, Chen W, Zhang J (2011) Water quality assessment by pollution-index method in the coastal waters of Hebei Province in western Bohai Sea, China. Mar Pollut Bull 62:2220-2229

Liu X, Ji C, Wang Q, Li F, Wu H (2014) Metabolic profiling of the tissue-specific responses in mussel Mytilus galloprovincialis towards Vibrio harveyi challenge. Fish Shellfish Immunol 39:372-377

Maas A, Seibel BA, Walsh PJ (2012) Effects of elevated ammonia concentrations on survival, metabolic rates, and glutamine synthetase activity in the Antarctic pteropod mollusk Clione limacina Antarctica. Polar Biol 35:1123-1128

Mazumder S, Plesca D, Almasan A (2008) Caspase-3 activation is a critical determinant of genotoxic stress-induced apoptosis. In: Mor G, Alvero AB (Eds) Methods in molecular biology. Apoptosis and Cancer (C) Humana Press Inc, Totowa NJ, pp. 13-21. vol. 414

Mizuguchi T, Mitaka T, Hirata K (2015) Role of branched chain amino acids in cellular and organ damage: the prognostic significance of the preoperative branched chain amino acid to tyrosine ratio. In: Rajendram R, Preedy VR, Patel VB (Eds) Branched chain amino acids in clinical nutrition, nutrition and health. Springer, New York, pp. 65-77

Natalotto A, Sureda A, Maisano M, Spanò N, Mauceri A, Deudero S (2015) Biomarkers of environmental stress in gills of Pinna nobilis (Linnaeus 1758) from Balearic Island. Ecotox Environ Safe 122:9-16

Nesic OB, Magoski NS, McKenney KK, Syed NI, Lukowiak K, Bulloch AGM (1996) Glutamate as a putative neurotransmitter in the mollusc, Lymnaea stagnalis. Neuroscience 75:1255-1269

Parsons HM, Ludwig C, Gunther UL, Viant M (2007) Improved classification accuracy in 1- and 2-dimensional NMR metabolomics data using the variance stabilizing generalised logarithm transformation. BMC Bioinformatics 8:234

Pellerin L, Magistretti PJ (1994) Glutamate uptake into astrocytes stimulates aerobic glycolysis: a mechanism coupling neuronal activity to glucose utilization. Proc Natl Acad Sci USA 91:10625-10629

Portera AG, Jänicke RU (1999) Emerging roles of caspase-3 in apoptosis. Cell Death Differ 6:99-104

Randall DJ, Tsui TKN (2002) Ammonia toxicity in fish. Mar Pollut Bull 45:17-23

Reddy-Lopata K, Auerswald L, Cook P (2006) Ammonia toxicity and its effect on the growth of the South African abalone Haliotis midae Linnaeus. Aquaculture 261:678-687
Shen Z-W, Cao Z, You K-Z, Yang Z-X, Xiao Y-Y, Cheng X-F, Chen Y-W, Wu R-H (2012) Quantification of choline concentration following liver cell apoptosis using $\sim 1 \mathrm{H}$ magnetic resonance spectroscopy. World J Gastroentero 18:1130-1136

UNEP/RAMOGE (1999) Manual on the biomarkers recommended for the MED POL biomonitoring programme. UNEP, Athens, p 1-92

Vetharaniam I, Thomson RA, Devine CE, Daly CC (2010) Modelling muscle energy-metabolism in anaerobic muscle. Meat Sci $85: 134-148$

Wang X (1989) Tolerance of the blood cockle (Anadara Granosa L.) and Phillippine clam (Ruditapes Adams et Reeve) to ammonia in sediments. Mar Sci 6:51-54. (in Chinese with English abstract)

Wang X, Wang L, Yao C, Qiu L, Zhang H, Zhou Z, Song L (2012) Alternation of immune parameters and cellular energy allocation of Chlamys farreri under ammonia-N exposure and Vibrio anguillarum challenge. Fish Shellfish Immunol 32:741-749

Watanabe S, Kodama M, Fukuda M (2009) Nitrogen stable isotope ratio in the manila clam, Ruditapes philippinarum, reflects eutrophication levels in tidal flats. Mar Pollut Bull 58:1447-1453

Widman J, Meseck S, Sennefelder G, Veilleux D (2008) Toxicity of un-ionized ammonia, nitrite, and nitrate to juvenile bay scallops, Argopecten irradians. Arch Environ Con Tox 54:460-465

Wu H, Southam AD, Hines A, Viant MR (2008) High throughput tissue extraction protocol for NMR and mass spectrometry based metabolomics. Anal Biochem 372:204-212

Wurtman RJ, Cansev M, Ulus IH (2010) Choline and its products acetylcholine and phosphatidylcholine. In: Lajtha A, Tettamanti G, Goracci G (Eds) Handbook of neurochemistry and molecular neurobiology. Springer, New York, US, pp 445-480

Yang Y, Zen M, Hu G-H, Lan G, Lu D, Li P, Feng J, Zhong C-G (2012) Cr (VI) induces the decrease of ATP level and the increase of apoptosis rate mediated by ROS or VDAC1 in L-02 hepatocytes. Environ Toxicol Phar 34:579-587

Yen C-LE, Mar M-H, Meeker RB, Fernandes A, Zeisel SH (2001) Choline deficiency induces apoptosis in primary cultures of fetal neurons. FASEB J 15:1704-1710

Zhang H, Pan L, Tao Y (2014) Toxicity assessment of environmental pollutant phenanthrene in clam Venerupis philippinarum using oxidative stress biomarkers. Environ Toxicol Phar 37:697-704

Zhang Z, Li X (2006) Evaluation of the effects of grading and starvation on the lysosomal membrane stability in Pacific oysters, Crassostrea gigas (Thunberg) by using neutral red retention assay. Aquaculture 256:537-541

Zhou H, Wang L, Shi X, Zhang H, Gao Y, Wang M, Kong P, Qiu L, Song L (2011) The modulation of catecholamines to the immune response against bacteria Vibrio anguillarum challenge in scallop Chlamys farreri. Fish Shellfish Immunol 31:1065-1071 